ARTICLE

Received 9 Oct 2015 | Accepted 7 Jan 2016 | Published 19 Feb 2016

\title{
A competitive and reversible deactivation approach to catalysis-based quantitative assays
}

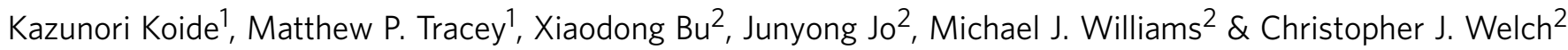

Catalysis-based signal amplification makes optical assays highly sensitive and widely useful in chemical and biochemical research. However, assays must be fine-tuned to avoid signal saturation, substrate depletion and nonlinear performance. Furthermore, once stopped, such assays cannot be restarted, limiting the dynamic range to two orders of magnitude with respect to analyte concentrations. In addition, abundant analytes are difficult to quantify under catalytic conditions due to rapid signal saturation. Herein, we report an approach in which a catalytic reaction competes with a concomitant inactivation of the catalyst or consumption of a reagent required for signal generation. As such, signal generation proceeds for a limited time, then autonomously and reversibly stalls. In two catalysis-based assays, we demonstrate restarting autonomously stalled reactions, enabling accurate measurement over five orders of magnitude, including analyte levels above substrate concentration. This indicates that the dynamic range of catalysis-based assays can be significantly broadened through competitive and reversible deactivation.

\footnotetext{
${ }^{1}$ Department of Chemistry, University of Pittsburgh, 219 Parkman Avenue, Pittsburgh, Pennsylvania 15260, USA. ${ }^{2}$ Process and Analytical Chemistry, Merck Research Laboratories, 126 East Lincoln Avenue, Rahway, New Jersey 07065, USA. Correspondence and requests for materials should be addressed to K.K. (email: koide@pitt.edu) or to C.J.W. (email: christopher_welch@merck.com).
} 
$\mathrm{D}$ evelopment of optical assays for facile quantification of trace analytes is an ever-expanding field. Target analytes range from trace metals ${ }^{1}$ and biological signalling agents $^{2,3}$ to chemical weapons ${ }^{4}$. Tailored chemosensors interact specifically with an analyte to produce an optically decoded signal, which can manifest itself as a wavelength shift or intensity change in either absorbance or emission. These signals are measured by simple instrumentation, such as a plate reader, or visualized with the naked eye.

Quantitative optical assays exploit either a catalytic or a noncatalytic reaction. Non-catalytic assays rely on a single turnover from the analyte for a chemical conversion or a reversible binding and have the benefit of time-independence; in other words, the signal does not change over time once the reaction or binding event is complete. A major drawback of these systems is the higher limits of quantification due to this limited turnover, rendering these non-catalytic assays undesirable for detection of trace analytes. A more sensitive approach for trace analytes uses catalysis-based assays, where the substrate continues to react over time, amplifying signals.

The continuity of catalysis-based signal amplification presents some practical challenges to assay development. In metal catalysis-based assays, once the metal has entered into the catalytic cycle, the resulting fluorescence signal is dependent on the concentration of the analyte as well as the time elapsed, with the reaction continuing until the fluorogenic substrate is consumed. In enzyme and enzyme-linked immunosorbent assays $^{5}$, the reaction continues until the substrate is consumed or a terminating reagent is added ${ }^{6}$. In either case, if an analyte is abundant, the assay substrate will be rapidly consumed, preventing accurate quantitation. In addition, if a reaction with a low concentration of analyte is allowed to continue unchecked, the signal can increase to the point where the detector becomes saturated, again preventing accurate quantification. Finally, when a catalysis-based assay is externally stopped, it cannot be restarted ${ }^{6}$ and premature termination requires the assay to be repeated to obtain quantitative data. As such, a significant drawback associated with catalysis-based assays is the far narrower dynamic range (one to two orders of magnitude) compared with more labour-intensive methods, such as inductively coupled plasma mass spectrometry (ICP-MS), which has a detection range is up to five orders of magnitude. New methodologies that overcome these limitations to enable controlled activity of catalytic assays would be broadly useful in chemical and biochemical research.

Herein, we present a new approach to catalysis-based assays in which a catalytic chromogenic reaction competes with the deactivation of the catalyst or depletion of an essential reagent. Under these conditions, a signal-producing reaction proceeds for a limited time, then autonomously stalls, but can be reactivated by reagent addition, generating a graph reminiscent of a staircase function in mathematics. This approach is exemplified by both a new colorimetric method for quantifying palladium $(\mathrm{Pd})$ and a horseradish peroxidase assay system. In the analysis of $\mathrm{Pd}$, multiple cycles of reaction stalling and restarting allow accurate measurement with a detection range of over five orders of magnitude. Moreover, analyte levels significantly above the substrate concentration can be quantified.

\section{Results}

Resorufin allyl ether as a chemodosimeter for palladium. We previously reported a fluorescence method for quantifying Pd in pharmaceuticals based on the Pd-catalysed fluorogenic conversion of allyl Pittsburgh Green ether (APE) to Pittsburgh Green (Fig. 1a) ${ }^{7-10}$. Although this method showed excellent sensitivity and an ability to accurately quantify low-level Pd in real-world samples, we realized that a colorimetric version of the assay could allow even simpler, instrument-free access to low-level Pd measurements, a goal previously attempted by several other researchers with limited success ${ }^{11,12}$.

Investigation of a number of candidate chromogenic substrates led to the preparation of yellow-coloured resorufin allyl ether (RAE) in one step in $85 \%$ yield from commercially available purple-coloured resorufin (Fig. 1b,c, Supplementary Figs 13 and 14). Attempts at Pd-catalysed deallylation of RAE using the optimized conditions for APE (tris(2-furyl)phosphine (TFP)), $\mathrm{NaBH}_{4}$, dimethyl sulphoxide (DMSO)/1.23 M phosphate $\mathrm{pH} 7$ buffer (1:9)) were unsuccessful. However, screening a variety of commercially available phosphines and additives (Supplementary Table S1 and Supplementary Figs 1-3) led to the identification of suitable conditions for carrying out the transformation. Optimized conditions for the Pd-dependent deallylation of RAE used TFP, $\mathrm{NH}_{4} \mathrm{OAc}$ and $\mathrm{NaBH}_{4}$ in an EtOH solvent. Further optimization of RAE as a substrate can be found in the Supplementary Methods and Supplementary Figs 2-4.

We found that RAE was selectively responsive to Pd over other metals tested ( $\mathrm{Ag}, \mathrm{Au}, \mathrm{Cd}, \mathrm{Co}, \mathrm{Cr}, \mathrm{Fe}, \mathrm{Hg}, \mathrm{Mn}, \mathrm{Ni}$. Pt, Rh, Ru, Zn, Sr, Ir, Cu; Supplementary Fig. 4a,b) and could detect Pd without interference from these metals, with the exception of $\mathrm{Hg}$, where a small level of interference was observed (Supplementary Fig. 4c). When selectivity was tested by absorbance, higher values were observed in the presence of $\mathrm{Au}, \mathrm{Ag}$, and $\mathrm{Hg}$ owing to turbidity of the solution, although fluorescence measurement revealed that these were merely false positives (that is, these metals did not convert RAE to resorufin; Supplementary Fig. 4a,b). When exposed to $\mathrm{Pd}$, the fluorescence signal increased linearly with respect to Pd concentration (Fig. 1d), indicating a first-order relationship suitable for convenient quantification.

The Pd-catalysed deallylation of APE in phosphate buffer was more effective in the presence of $\mathrm{NaBH}_{4}$, which reduces $\mathrm{Pd}(\mathrm{II})$ and $\operatorname{Pd}(\mathrm{IV})$ to catalytically active $\mathrm{Pd}(0)$, but did not require this reducing agent as a critical component ${ }^{9}$. In contrast, $\mathrm{Pd}(\mathrm{II})$ species did not catalyse the deallylation of $\mathrm{RAE}$ in $\mathrm{NH}_{4} \mathrm{OAc}$-containing $\mathrm{EtOH}$ without the reducing agent, with the amount of $\mathrm{NaBH}_{4}$ dictating the duration of reaction (Fig. 2a). This novel $\mathrm{NaBH}_{4}$ dependence boded well with our aim at competitively and reversibly deactivating catalysis-based assays, as detailed below. Lower concentrations of $\mathrm{NaBH}_{4}$, ranging from $5-25 \mathrm{mM}$, led to stalling of the colour-forming reaction within $30 \mathrm{~s}$, presumably because of rapid consumption of the reductant, $\mathrm{NaBH}_{4}$, combined with ongoing air-oxidation of catalytically active $\mathrm{Pd}(0)$ to higher valent, inactive $\mathrm{Pd}$ species. In contrast, $\mathrm{NaBH}_{4}$ concentrations in excess of $50 \mathrm{mM}$ allowed the reaction to continue for several minutes. Importantly, the addition of more $\mathrm{NaBH}_{4}$ could restart a stalled deallylation reaction (Fig. 2b), affording a convenient way to trigger signal generation on demand.

Subsequently, we sought to gain insights into the reaction stalling to rationally expand this developing methodology. The Pd-catalysed deallylation of APE stalled in the presence of $\mathrm{NH}_{4} \mathrm{OAc}$ but continued in a phosphate buffer (Supplementary Fig. 6). With 200, 400, 600 and $800 \mathrm{mM} \mathrm{NH}_{4} \mathrm{OAc}$ followed by $\mathrm{pH}$ adjustment, the reactions stalled nearly at the same time (Supplementary Fig. 7). The Pd-catalysed deallylation reaction of RAE under a nitrogen atmosphere were found to stall more slowly than those carried out in open air (Supplementary Fig. 8), suggesting that aerobic oxidation of $\operatorname{Pd}(0)$ to higher order $\mathrm{Pd}$ species may account for the observed reaction stalling.

Demonstration of stop-and-go methodology with RAE. In an effort to develop a simple, user-friendly colorimetric Pd 
a Previous work: continuous fluorometric reaction<smiles>C=CCOc1cc2c(cc1Cl)C1(OCc3ccccc31)c1cc(Cl)c(O)cc1O2</smiles>
(APE)

b

This work: autonomously stalling colorimetric reaction

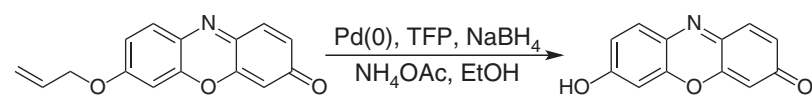

Resorufin allyl ether (RAE)

Resorufin
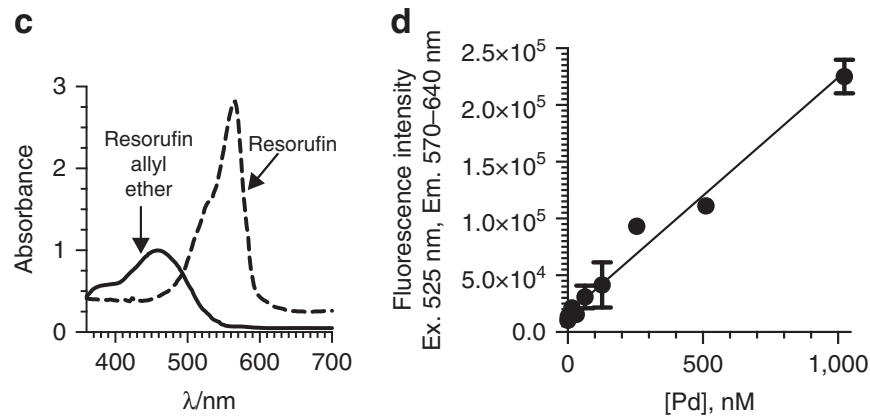

Figure 1 | Palladium chemodosimeters based on change in optical properties. (a) Structures of previously developed fluorogenic chemodosimeter APE and its conversion to Pittsburgh Green. (b) Chromogenic chemodosimeter RAE and its conversion to resorufin. (c) Absorption spectra of resorufin and RAE in $800 \mathrm{mM} \mathrm{NH}_{4} \mathrm{OAc}$ in EtOH. The data are normalized to $20 \mu \mathrm{M}$ of each compound. (d) Correlation between Pd concentrations and fluorescence signal using RAE. $r^{2}=0.97, y=(208 \pm 7.38) x+(15,910 \pm 2,765)$. Conditions: $29 \mu \mathrm{M} \mathrm{RAE}, 0,8,16,32,64,128,256,512,1,024 \mathrm{nM} \mathrm{Pd}(\mathrm{II}) .50 \mathrm{mM} \mathrm{NaBH} 4,200 \mu \mathrm{M}$ TFP, $800 \mathrm{mM} \mathrm{NH}_{4} \mathrm{OAc}$, EtOH, $24^{\circ} \mathrm{C}, 60 \mathrm{~min} ; n=3$.
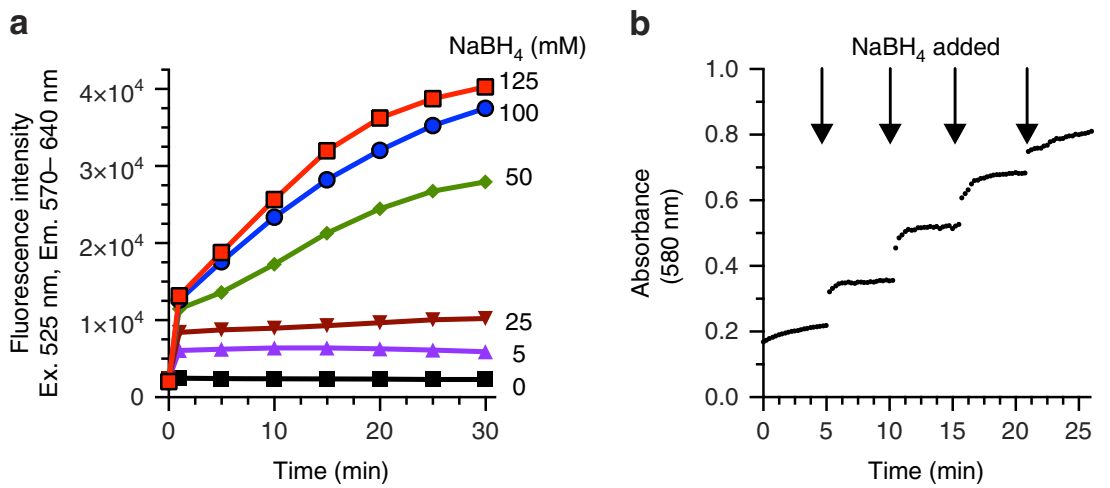

Figure 2 | Influence of $\mathbf{N a B H}_{4}$ on deallylation of RAE. (a) Reaction lifetime dictated by $\mathrm{NaBH}_{4}$ concentration. Conditions: $29 \mu \mathrm{M} \mathrm{RAE}, 10$ p.p.b. Pd(II), $200 \mu \mathrm{M}$ TFP, $800 \mathrm{mM} \mathrm{NH}_{4} \mathrm{OAc}, 0-125 \mathrm{mM} \mathrm{NaBH}_{4}, \mathrm{EtOH}, 25^{\circ} \mathrm{C}$. (b) Stalled deallylation reaction can be restarted by $\mathrm{NaBH}_{4}$ addition. Conditions: $29 \mu \mathrm{M}$ RAE, 0.3 p.p.m. Pd(II), $200 \mu \mathrm{M}$ TFP, $800 \mathrm{mM} \mathrm{NH}_{4} \mathrm{OAc}, 0.0 .6,1.2,1.8,2.4 \mathrm{mM} \mathrm{NaBH}_{4}$, added as $2.5 \mathrm{M}$ aliquots at indicated time points.

quantification assay, we prepared a reagent cocktail combining all reaction components except $\mathrm{NaBH}_{4}$ in a single solution. This cocktail, which is stable for over 2 weeks when stored at $5^{\circ} \mathrm{C}$, can be dispensed as needed, simplifying application of the colorimetric method. The addition of either $20 \mu \mathrm{l}$ of a solution or $2-5 \mathrm{mg}$ of a solid sample containing trace $\mathrm{Pd}$ to $1 \mathrm{ml}$ of the reaction cocktail, followed by the addition of a $\mathrm{NaBH}_{4}$ solution, generated colour and fluorescence within $1 \mathrm{~min}$. The colour intensity was linearly correlated with Pd concentration, and the dynamic range and reaction time of the assay were tailored by adjusting the $\mathrm{NaBH}_{4}$ concentration.

The power of this method is shown in Fig. 3. Known concentrations of $\mathrm{Pd}$ afford widely different colours with a single concentration of $\mathrm{NaBH}_{4}$, with the colour persisting for $24 \mathrm{~h}$ (Fig. 3a). If a sample contains 1 p.p.b. Pd, then $100 \mathrm{mM} \mathrm{NaBH}_{4}$ is required to observe a colour change (Fig. 3b). If a sample contains 10 p.p.m. Pd, then no $\mathrm{NaBH}_{4}$ is added to observe a colour change. Thus, $\mathrm{Pd}$ concentrations ranging from 1 p.p.b. to 10 p.p.m. (five orders of magnitude) can be distinguished in one reaction solution with $\mathrm{NaBH}_{4}$ titration. Alternatively, a user may prepare multiple wells with variable $\mathrm{NaBH}_{4}$ amounts and count a number of coloured wells to estimate the Pd concentrations.

To confirm that the stop-and-go assay approach is providing quantitative data, we analysed real-world samples. We first tested intermediates used in the preparation of active pharmaceutical 
a

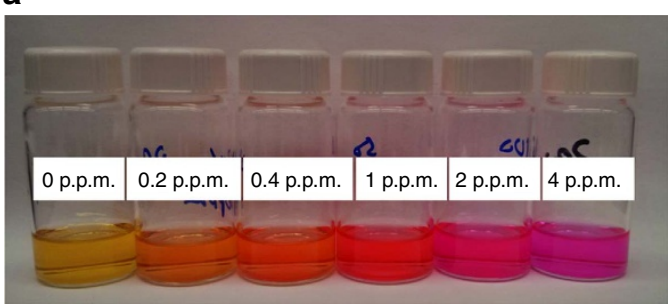

b

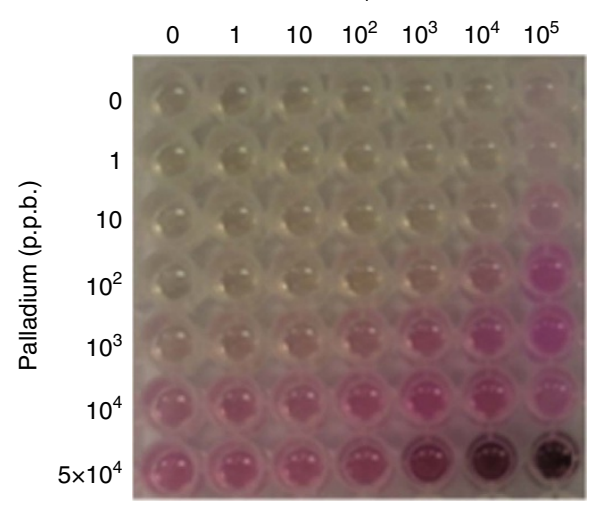

c

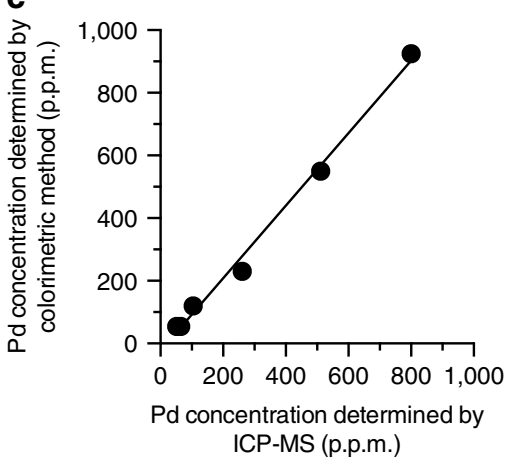

Figure 3 | Visual quantification of palladium with RAE. (a) The appearance of distinguishable colour correlating to Pd concentration occurs in less than $1 \mathrm{~min}$ using a set of $\mathrm{Pd}$ standards. Conditions: $29 \mu \mathrm{M} \mathrm{RAE}$, 0-4.0 p.p.m. Pd, $200 \mu \mathrm{M}$ TFP, $800 \mathrm{mM} \mathrm{NH}_{4} \mathrm{OAc}, 1.0 \mathrm{mM} \mathrm{NaBH}_{4}$, EtOH, $25^{\circ} \mathrm{C}$. (b) Colorimetric plate showing dependence of colour formation on $\mathrm{Pd}$ and $\mathrm{NaBH}_{4}$ concentration; $29 \mu \mathrm{M} \mathrm{RAE}, 200 \mu \mathrm{M}$ TFP, 0-50 p.p.m. $\mathrm{Pd}, 0-100 \mathrm{mM} \mathrm{NaBH}_{4}, 800 \mathrm{mM} \mathrm{NH}_{4} \mathrm{OAc} 25^{\circ} \mathrm{C}, \mathrm{EtOH}, 10 \mathrm{~min}, n=3$.

(c) Conditions: colorimetric analysis as reported in Fig. 4a; ICP-MS analysis as reported in the 'Methods' section. ingredients. In pharmaceutical synthesis, reactions may leave behind residual $\mathrm{Pd}$ in the products, which is often difficult to remove ${ }^{13}$. Various samples were tested from active projects in the Process and Analytical Chemistry Department at Merck Research Laboratories in which residual Pd removal has proven difficult. Quantification of Pd was initially performed by ICP-MS followed by analysis using RAE. Compared with the ICP-MS analysis, the stop-and-go approach with RAE provided accuracy from 70 to $120 \%$, with residual $\mathrm{Pd}$ concentrations ranging from 62 to 800 p.p.m. (Fig. 3c). These results were satisfactory for this assay approach to be used for screening dozens of routine $\mathrm{Pd}$ remediation protocols.

Microscale screening of process adsorbents is often used to identify resins or activated carbons that can be used for selective adsorption of metal impurities in pharmaceutical process research and development ${ }^{14,15}$. Traditionally, this approach requires close coordination with ICP-MS specialists to allow for quick turnaround time. However, often because of instrument calibration, the vast number of samples, and preparation time, this can be time consuming. As such, the pharmaceutical industry has been interested in a faster technology for trace metal analysis $^{16}$.

The application of the colorimetric method enables rapid determination of $\mathrm{Pd}$ concentrations 'on the spot', in the same laboratory where the process development studies are being carried out. Figure 4 shows the results of a high throughput screen of Pd impurity remediation treatments of a pharmaceutical intermediate with 48 metal-scavenging adsorbents, using the stop-and-go assay with RAE to visualize relative Pd levels. An aliquot from each well is treated with the reaction cocktail (Fig. 4a), then with $\mathrm{NaBH}_{4}$. In less than $5 \mathrm{~min}$, gross differences in $\mathrm{Pd}$ concentration are readily apparent to the naked eye by distinguishable colours (Fig. 4b). At this point, the reaction had stalled, and too many hits were identified. Accordingly, more $\mathrm{NaBH}_{4}$ was added to restart the reaction, accentuating the differences between wells and enabling rapid determination of the potential most-effective treatments for residual Pd remediation (Fig. 4c). A high-throughput mapping of relative $\mathrm{Pd}$ concentration was obtained by plotting the ratio of absorbance at 580 and $460 \mathrm{~nm}$ using a ultraviolet-visible plate reader (read time for 48 samples $<30 \mathrm{~s}$; Fig. $4 \mathrm{~d}$ ). These results quantitatively confirm the most effective $\mathrm{Pd}$ removal treatments to be wells A5, C4, E6, F3 and F5. Spot-checking several adsorbent treatment samples using conventional ICP-MS showed a good correlation with the colorimetric method, with the selection of the most-effective adsorbent treatments (A5, E6) being identical in both cases. These results demonstrate the utility of a stop-and-go approach in trace metal quantification, providing an important a

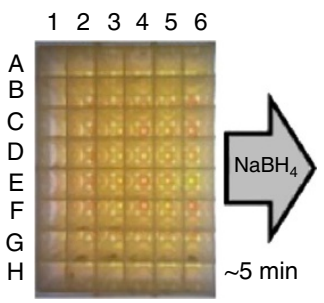

b

123456

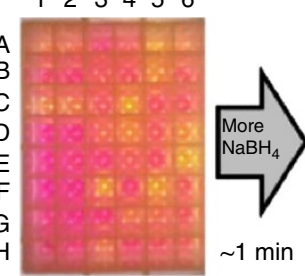

C

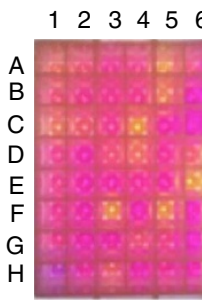

d

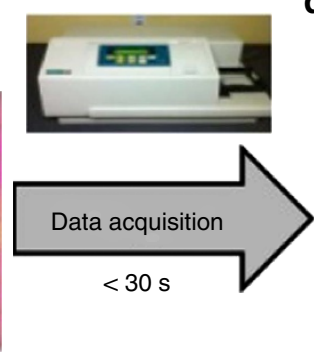

Ratio $\left(A_{580} \mathrm{~nm} / A_{460} \mathrm{~nm}\right)$
\begin{tabular}{|c|c|c|c|c|c|c|}
\hline & 1 & 2 & 3 & 4 & 5 & 6 \\
\hline $\mathrm{A}$ & 1.4 & 3.3 & 5.0 & 5.0 & 0.4 & 2.0 \\
\hline $\mathrm{B}$ & 5.0 & 5.0 & 5.0 & 5.0 & 0.7 & 5.0 \\
\hline $\mathrm{C}$ & 1.0 & 3.3 & 5.0 & 0.6 & 5.0 & 5.0 \\
\hline $\mathrm{D}$ & 5.0 & 5.0 & 2.5 & 1.0 & 5.0 & 1.7 \\
\hline $\mathrm{E}$ & 5.0 & 5.0 & 5.0 & 5.0 & 5.0 & 0.4 \\
\hline $\mathrm{F}$ & 5.0 & 5.0 & 0.5 & 5.0 & 0.5 & 5.0 \\
\hline $\mathrm{G}$ & 5.0 & 5.0 & 5.0 & 2.5 & 3.3 & 5.0 \\
\hline $\mathrm{H}$ & 3.3 & 5.0 & 1.4 & 5.0 & 5.0 & 5.0 \\
\hline
\end{tabular}

Figure 4 | Case study of a streamlined process combining adsorbent screening for Pd removal with high-throughput colorimetric Pd detection. (a) Screening kits containing 48 commercial adsorbents ${ }^{15}$ are exposed to a solution of a Pd-containing intermediate. (b) Aliquots from screening kits are evaluated for $\mathrm{Pd}$ content using the colorimetric method, as described in protocol. (c) Finding the best potential hits visually by adding more $\mathrm{NaBH}_{4}$. (d) High-throughput mapping of relative Pd concentration by measurement of ultraviolet-visible $570 \mathrm{~nm} / 460 \mathrm{~nm}$ using ultraviolet-visible plate reader. 
advance for process chemists dealing with remediation of $\mathrm{Pd}$ impurity problems using point-of-use high-throughput analysis.

We previously applied APE for quantifying Pd in ore samples without requiring acidic sample digestion ${ }^{17}$, a significant improvement over standard analytical methods such as ICPMS, but still requiring the use of a blue light source to check fluorescence intensity. This requirement associated with the fluorometric method was not ideal for turbid samples such as ores. Therefore, we applied our colorimetric method for more convenient visualization. We found that the reaction was stalled before effective Pd extraction from the ores, leading to a need to add a large excess of $\mathrm{NaBH}_{4}$. However, a 1-min pre-incubation in a DMSO solution of TFP with sonication, followed by the addition of RAE, $\mathrm{NH}_{4} \mathrm{OAc}, \mathrm{EtOH}$ and $\mathrm{NaBH}_{4}$ afforded subpar semi-quantitative data. A second addition of $\mathrm{NaBH}_{4}$ after the reaction had stalled provided good colorimetric agreement with previous semi-quantitative analysis ${ }^{17}$ (Supplementary Fig. 9) within $20 \mathrm{~min}$.

Trace Pd is also a significant concern in materials science ${ }^{18,19}$. Our colorimetric method could be used to successfully detect trace $\mathrm{Pd}$ in polymer materials, as shown in Supplementary Figs 10-12, Supplementary Table 2 and Supplementary Notes 1 and 2 .

Competitive and reversible deactivation in enzymatic assay. Horseradish peroxidase (HRP) is a common enzyme for detection and quantification in biological assays ${ }^{20,21}$. This enzyme catalytically converts Amplex Red (10-acetyl-3,7dihydroxyphenoxazine) and $\mathrm{H}_{2} \mathrm{O}_{2}$ to resorufin, acetic acid and
$\mathrm{H}_{2}$ O. (Fig. 5a) $)^{22}$. The reaction continues indefinitely until either Amplex Red or $\mathrm{H}_{2} \mathrm{O}_{2}$ is consumed, at which point, signal generation is stopped.

To illustrate the discontinuous catalysis approach in a different assay, we designed a system in which $\mathrm{PhB}(\mathrm{OH})_{2}$ would competitively reduce $\mathrm{H}_{2} \mathrm{O}_{2}$ (Fig. 5a 'Deactivation of reagent') while the $\mathrm{H}_{2} \mathrm{O}_{2}$-mediated oxidation of Amplex Red occurs ('Conventional HRP assay'). Figure 5b shows that $\mathrm{PhB}(\mathrm{OH})_{2}$ was able to do so in a concentration-dependent manner, affording lower signals. Reactions halted by consumption of $\mathrm{H}_{2} \mathrm{O}_{2}$ could be restarted by an addition of a fresh aliquot of $\mathrm{H}_{2} \mathrm{O}_{2}$ (Fig. $5 \mathrm{c}$ ). With a further addition of $\mathrm{H}_{2} \mathrm{O}_{2}$, signal saturation occurred (Fig. 5d). With the inclusion of the competitive scavenger, $\mathrm{PhB}(\mathrm{OH})_{2}$ to remove $\mathrm{H}_{2} \mathrm{O}_{2}$ from the system, the discontinuous catalysis alleviated the problem of overshooting signals, as well as allowed us to restart the reaction without problematic increases in fluorescence (Fig. 5d). Although the protocol has not been fully optimized in an HRP system, these data indicate a great potential for the applications of discontinuous catalysis in other enzyme assays.

\section{Discussion}

We have developed a competitive and reversible deactivation approach for catalytic quantification assays (Fig. 6). Conversion of RAE to resorufin via a Pd-catalysed Tsuji-Trost reaction is autonomously stalled by the oxidation of reactive $\operatorname{Pd}(0)$ to non-reactive species. The addition of $\mathrm{NaBH}_{4}$ as a reducing agent is able to restart the reaction, enabling accurate measurements over five orders of magnitude. Notably, even in cases where the a

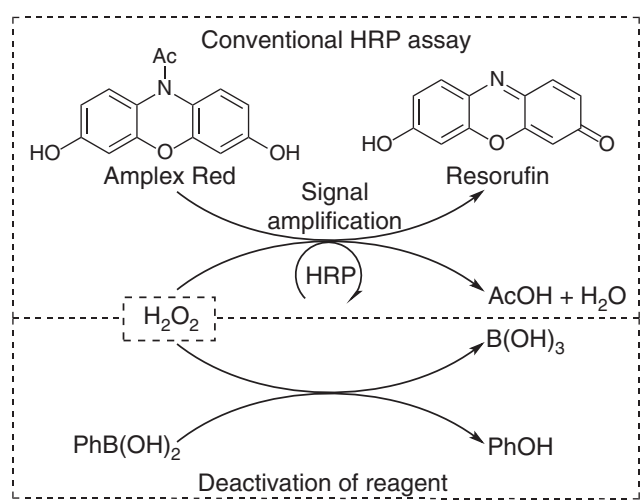

b

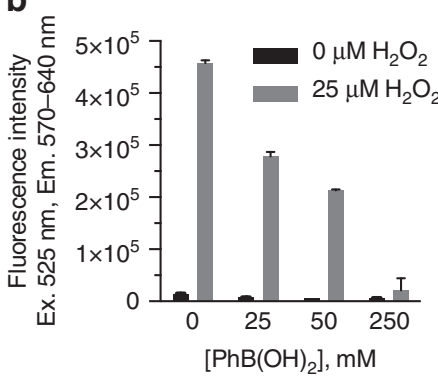

C

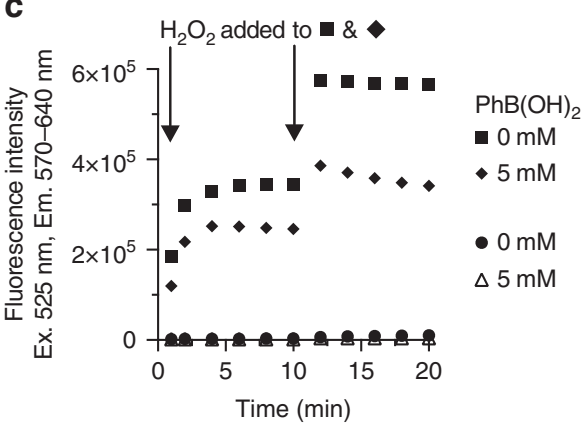

d

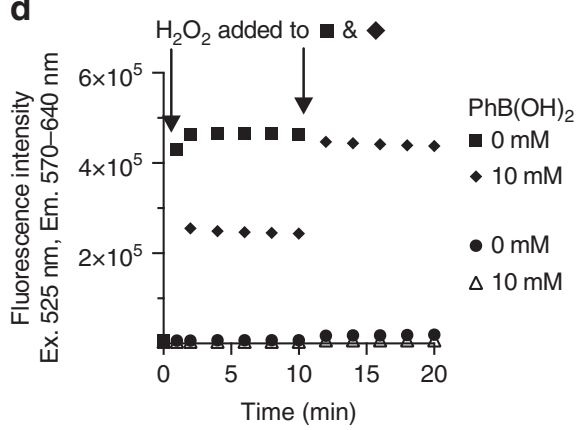

Figure 5 | Stop-and-go approach in a horseradish peroxidase system. (a) Conversion of Amplex Red to resorufin. (b) Effect of $\mathrm{PhB}(\mathrm{OH})_{2}$ on horseradish peroxidase assay. Conditions: $50 \mu \mathrm{M}$ Amplex Red, $0.1 \mathrm{Uml}^{-1}$ horseradish peroxidase, $\left.25 \mu \mathrm{M} \mathrm{H}_{2} \mathrm{O}_{2}, 0,25,50,250 \mathrm{mM} \mathrm{PhB(OH}\right)_{2}, \mathrm{PBS} \mathrm{pH} 7.4$.

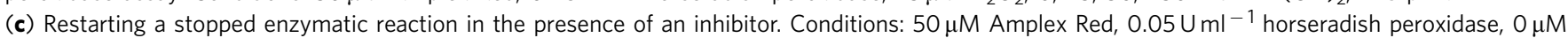
$\mathrm{H}_{2} \mathrm{O}_{2}$ (0-20 min) for the circle and triangle. For others, $10 \mu \mathrm{M} \mathrm{H}_{2} \mathrm{O}_{2}$ at 0 min, $20 \mu \mathrm{M} \mathrm{H}_{2} \mathrm{O}_{2}$ at 10 min, PBS pH 7.4. (d) Restarting a stopped enzymatic reaction in the presence of an inhibitor with uninhibited saturation. Conditions: $50 \mu \mathrm{M} \mathrm{Amplex} \mathrm{Red,} 1 \mathrm{Uml}^{-1}$ horseradish peroxidase, $0 \mu \mathrm{M} \mathrm{H} \mathrm{H}_{2}$ ( $0-20 \mathrm{~min}$ ) for the circle and triangle. For others, $10 \mu \mathrm{M} \mathrm{H}_{2} \mathrm{O}_{2}$ at $0 \mathrm{~min}, 30 \mu \mathrm{M} \mathrm{H}_{2} \mathrm{O}_{2}$ at $10 \mathrm{~min}, \mathrm{PBS} \mathrm{pH}$ 7.4. After the addition of $\mathrm{H}_{2} \mathrm{O}_{2}$ at 10 min, the $\mathrm{PhB}(\mathrm{OH})_{2}$-free sample (square) showed a signal above the upper limit of the instrument (above $2 \times 10^{6}$ units). 
a Conventional catalysis-based assays
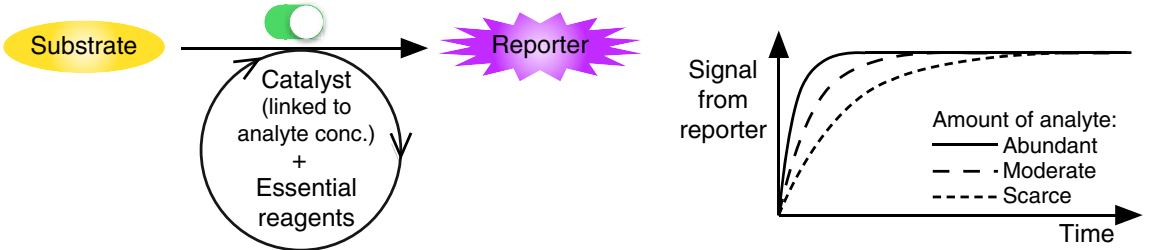

b This work
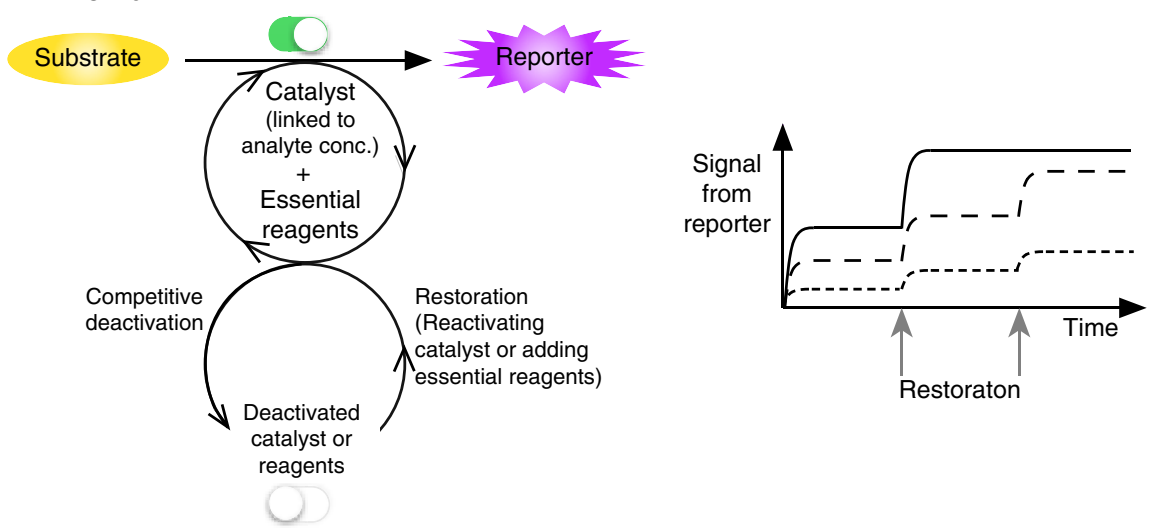

Figure 6 | Continuous reaction and competitively and reversibly deactivated reaction. (a) Widely used catalytic assays continuously convert a substrate to a reporter molecule. (b) This work presents a stop-and-go paradigm, in which there is a competition between the catalytic reaction and autonomous deactivation of the catalyst (that is, analyte) or the essential reagent. The addition of an activator or a reactant restores the system.

amount of Pd far exceeds the amount of RAE, the data remain quantitative. We have also demonstrated the utility of the same concept in a widely used HRP assay system, where competitive destruction of $\mathrm{H}_{2} \mathrm{O}_{2}$ by $\mathrm{PhB}(\mathrm{OH})_{2}$ leads to reaction stalling, broadening the dynamic range of the assay. These approaches should be compatible with automation and may find further applicable arenas to broaden the dynamic ranges of catalysisbased assays.

\section{Methods}

Ultraviolet-visible spectroscopy. The ultraviolet-visible spectra of RAE and resorufin solutions were acquired using a diode array spectrophotometer (Agilent Technologies, Santa Clara, CA) in a quartz cuvette. Other absorbance measurements were recorded in either a 96-well plate using a Modulus II Microplate Multimode reader (Promega, Madison, WI) measuring absorbance at $560 \mathrm{~nm}$ or in a clear, round bottom 96-well plates on a Spectra Max M5 spectrometer (Molecular Devices, Sunnyvale, CA) under the control of a Windows-based PC running software pro V5. The samples were analysed at $\lambda=580 \mathrm{~nm}$ for the resorufin, and at $\lambda=525 \mathrm{~nm}$ for RAE

Fluorescence measurement. Fluorescence measurements were read on a Modulus II Microplate Multimode Reader (excitation $525 \mathrm{~nm}$, emission $580-640 \mathrm{~nm}$ ) or using a HoribaMax Fluorometer (excitation $578 \mathrm{~nm}$, emission $350-700 \mathrm{~nm})$.

Metal analysis by ICP-MS. The samples were either diluted or suspended directly in concentrated nitric acid or evaporated with a rotary evaporator first and then re-dissolved in concentrated nitric acid for ICP-MS analysis. Depending on the concentration range of the element, either a Perkin-Elmer Elan 6000 quadrupole ICP-MS spectrometer (Perkin-Elmer, Norwalk, CT) or a Thermo Finnigan Element 2 high-resolution ICP-MS spectrometer (Finnigan, Bremen, Germany) was used for the analysis.

General protocol for deallylation of RAE. A reaction cocktail was prepared by mixing $800 \mathrm{mM} \mathrm{NH}_{4} \mathrm{OAc}$ in EtOH $(10 \mathrm{ml})$ with $800 \mu \mathrm{M} \mathrm{RAE}$ in $\mathrm{EtOH}(400 \mu \mathrm{l})$ and $3 \mathrm{mM}$ TFP in DMSO, with 250 p.p.m. BHT $(800 \mu \mathrm{l})$. The reaction cocktail $(1 \mathrm{ml})$ was added to individual 2-ml Eppendorf tubes. To half of the samples was added $5 \%$ TraceMetal $\mathrm{HNO}_{3}(20 \mu \mathrm{l})$ as a control. To the other half of the samples was added a $\mathrm{Pd}^{2}+$ solution in $5 \%$ TraceMetal $\mathrm{HNO}_{3}(20 \mu \mathrm{l})$. To all the samples was added $\mathrm{NaBH}_{4}$ in $10 \mathrm{~N} \mathrm{NaOH}(20 \mu \mathrm{l})$. The samples were mixed and transferred $(200 \mu \mathrm{l})$ to a 96 -well black fluorescence well plate. Fluorescence (excitation $525 \mathrm{~nm}$, emission $570-640 \mathrm{~nm}$ ) was measured every $2 \mathrm{~min}$ for $60 \mathrm{~min}$ using a Modulus II Microplate Multimode Reader.

\section{References}

1. Carter, K. P., Young, A. M. \& Palmer, A. E. Fluorescent sensors for measuring metal ions in living systems. Chem. Rev. 114, 4564-4601 (2014).

2. Namiki, S., Sakamoto, H., Iinuma, S., Iino, M. \& Hirose, K. Optical glutamate sensor for spatiotemporal analysis of synaptic transmission. Eur. J. Neurosci. 25, 2249-2259 (2007).

3. Hettie, K. S., Liu, X., Gillis, K. D. \& Glass, T. E. Selective catecholamine recognition with NeuroSensor 521: a fluorescent sensor for the visualization of norepinephrine in fixed and live cells. ACS Chem. Neurosci. 4, 918-923 (2013).

4. Zhang, S. W. \& Swager, T. M. Fluorescent detection of chemical warfare agents: functional group specific ratiometric chemosensors. J. Am. Chem. Soc. 125, 3420-3421 (2003).

5. Goldberg, M. E. \& Djavadiohaniance, L. Methods for measurement of antibody antigen affinity based on ELISA and RIA. Curr. Opin. Immunol. 5, 278-281 (1993).

6. Demontellano, P. R. O., David, S. K., Ator, M. A. \& Tew, D. Mechanism-based inactivation of horseradish-peroxidase by sodium azide. Formation of mesoazidoprotoporphyrin IX. Biochemistry 27, 5470-5476 (1988).

7. Song, F. L., Garner, A. L. \& Koide, K. A highly sensitive fluorescent sensor for palladium based on the allylic oxidative insertion mechanism. J. Am. Chem. Soc. 129, 12354-12355 (2007).

8. Garner, A. L., Song, F. L. \& Koide, K. Enhancement of a catalysis-based fluorometric detection method for palladium through rational fine-tuning of the palladium species. J. Am. Chem. Soc. 131, 5163-5171 (2009).

9. Song, F. L., Carder, E. J., Kohler, C. C. \& Koide, K. Studies toward an ideal fluorescence method to measure palladium in functionalized organic molecules: effects of sodium borohydride, temperature, phosphine ligand, and phosphate ions on kinetics. Chemistry 16, 13500-13508 (2010).

10. Bu, X. D., Koide, K., Carder, E. J. \& Welch, C. J. Rapid analysis of residual palladium in pharmaceutical development using a catalysis-based fluorometric method. Org. Process Res. Dev. 17, 108-113 (2013).

11. Liu, W. et al. Water-soluble colorimetric and ratiometric fluorescent probe for selective imaging of palladium species in living cells. Inorg. Chem. 53, 12590-12594 (2014). 
12. Yang, M. P. et al. A novel selective fluorescent and colorimetric chemosensor for the visual detection of $\mathrm{Pd}^{2+}$ and application of imaging in living cells. Inorg. Chem. Commun. 46, 310-314 (2014).

13. Bullock, K. M., Mitchell, M. B. \& Toczko, J. F. Optimization and scale-up of a Suzuki-Miyaura coupling reaction: development of an efficient palladium removal technique. Org. Process Res. Dev. 12, 896-899 (2008).

14. Welch, C. J. et al. Adsorbent screening for metal impurity removal in pharmaceutical process research. Org. Process Res. Dev. 9, 198-205 (2005).

15. Wang, L. et al. Screening binary systems of chelating agents combined with carbon or silica gel adsorbents: the development of a cost-effective method to remove palladium from pharmaceutical intermediates and APIs. Org. Process Res. Dev. 15, 1371-1376 (2011).

16. Thayer, A. M. Trace metals debate. Chem. Eng. News 19, 10-13 (2013).

17. Williams, J. M. \& Koide, K. A high-throughput method to detect palladium in ores. Ind. Eng. Chem. Res. 52, 8612-8615 (2013).

18. Krebs, F. C., Nyberg, R. B. \& Jorgensen, M. Influence of residual catalyst on the properties of conjugated polyphenylenevinylene materials: palladium nanoparticles and poor electrical performance. Chem. Mater. 16, 1313-1318 (2004).

19. Nielsen, K. T., Bechgaard, K. \& Krebs, F. C. Removal of palladium nanoparticles from polymer materials. Macromolecules 38, 658-659 (2005).

20. Engvall, E., Jonsson, K. \& Perlmann, P. Enzyme-linked immunosorbent assay. II. Quantitative assay of protein antigen, immunoglobulin $\mathrm{G}$, by means of enzyme-labelled antigen and antibody-coated tubes. Biochim. Biophys. Acta 251, 427-434 (1971).

21. Engvall, E. \& Perlmann, P. Enzyme-linked immunosorbent assay (ELISA) quantitative assay of immunoglobulin-G. Immunochemistry 8, 871-874 (1971).

22. Zhou, M. J., Diwu, Z. J., PanchukVoloshina, N. \& Haugland, R. P. A stable nonfluorescent derivative of resorufin for the fluorometric determination of trace hydrogen peroxide: applications in detecting the activity of phagocyte NADPH oxidase and other oxidases. Anal. Biochem. 253, 162-168 (1997).

\section{Acknowledgements}

We thank Stillwater Mining Co. for the ore samples. We thank Professor Frederik Krebs for providing the polymer samples. We are grateful to the Merck Research Laboratories New Technologies Review \& Licensing Committee (NT-RLC) and to the US National Science Foundation (CHE-0911092 and CHE-1506942) for funding.

\section{Author contributions}

All the authors were involved in designing the experiments and analysing the data. M.P.T., X.B., J.J. and M.J.W. performed the experiments. All the authors contributed towards writing the manuscript.

\section{Additional information}

Supplementary Information accompanies this paper at http://www.nature.com/ naturecommunications

Competing financial interests: The authors declare no competing financial interests.

Reprints and permission information is available online at http://npg.nature.com/ reprintsandpermissions/

How to cite this article: Koide, K. et al. A competitive and reversible deactivation approach to catalysis-based quantitative assays. Nat. Commun. 7:10691 doi: 10.1038/ncomms10691 (2016).

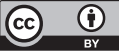

This work is licensed under a Creative Commons Attribution 4.0 International License. The images or other third party material in this article are included in the article's Creative Commons license, unless indicated otherwise in the credit line; if the material is not included under the Creative Commons license, users will need to obtain permission from the license holder to reproduce the material. To view a copy of this license, visit http://creativecommons.org/licenses/by/4.0/ 